\title{
The Epistemological Basis of Engineering, and its Reflection in the Modern Engineering Curriculum
}

\author{
Mike Murphy \\ Technological University Dublin, mike.murphy@tudublin.ie \\ William Grimson \\ Technological University Dublin
}

Follow this and additional works at: https://arrow.tudublin.ie/engineducbks

Part of the Engineering Education Commons, and the Other Engineering Commons

\section{Recommended Citation}

Murphy, M. \& Grimson, M. (2015). The Epistemological basis of engineering and Its reflection in the modern engineering curriculum. In: Christensen S. et al (eds) Engineering Identities, Epistemologies and Values. Philosophy of Engineering and Technology, vol 21. Springer. doi:https://doi.org/10.21427/ 69s8-rz54

This Book Chapter is brought to you for free and open access by the Engineering: Education and Innovation at ARROW@TU Dublin. It has been accepted for inclusion in Books/Book chapters by an authorized administrator of ARROW@TU Dublin. For more information, please contact arrow.admin@tudublin.ie, aisling.coyne@tudublin.ie,gerard.connolly@tudublin.ie.

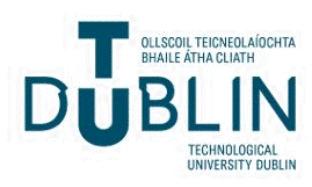


This article is a near-last version of a chapter that has been published as: Grimson W., Murphy M. (2015) The Epistemological Basis of Engineering, and Its Reflection in the Modern Engineering Curriculum. In: Christensen S., Didier C., Jamison A., Meganck M., Mitcham C., Newberry B. (eds) Engineering Identities, Epistemologies and Values. Philosophy of Engineering and Technology, vol 21. Springer

\title{
The Epistemological Basis of Engineering, and its Reflection in the Modern Engineering Curriculum
}

\author{
William Grimson and Mike Murphy
}

\begin{abstract}
Perhaps unlike other professions, engineering is strangely difficult to define or describe. This is nowhere as evident as when an attempt is made to articulate its epistemological basis. Engineering has a rich and complex 'gene pool' which goes back to when people first built shelters and shaped implements for agricultural purposes. Throughout the ages one constant characteristic of engineering has been its readiness to avail of whatever material is on hand together with whatever knowledge or skill is available to meet the challenge of enhancing an object or making something which never previously existed. On occasion engineers have created new knowledge but for the most part they have been users of knowledge: borrowing from nature, science, mathematics, arts in order to meet their requirements to solve specific problems. The art of engineering is in the appropriate selection of knowledge coupled with an ability to use that knowledge in achieving an objective. A three-layer model is proposed to describe the epistemological basis of engineering. This layer consists of a foundational layer containing subject material such as mathematics and science, above which is a middle-layer largely populated by domain knowledge associated with engineering program learning outcomes, and with the final top layer acting as a capstone and expressed in terms of professional competences.
\end{abstract}

Keywords: knowledge, engineering education, learning outcomes, competences, professional engineers, epistemology, heuristics.

\section{Introduction}

The ideal engineer is a composite ... He is not a scientist, he is not a mathematician, he is not a sociologist or a writer; but he may use the knowledge and techniques of any or all of these disciplines in solving engineering problems. (N.W. Dougherty)

Engineering is not merely knowing and being knowledgeable, like a walking encyclopedia; engineering is not merely analysis; engineering is not merely the possession of the capacity to get elegant solutions to non-existent engineering problems; engineering is practicing the art of the organized forcing of technological change... Engineers operate at the interface between science and society... (Dean Gordon Brown) 
These two quotations point to the character of engineering that makes it so difficult to draw boundaries around both its fundamental nature and, as a consequence, its epistemological foundations. On the one hand engineering uses whatever knowledge is relevant, whatever its origin, to address a particular challenge. In that sense the totality of available knowledge (the body of knowledge) is in principle the epistemological basis of engineering. On the other hand that body of knowledge by virtue of its sheer extent is unknowable to or by the individual engineer. Described another way, if the duration of engineering degree programs matched the general explosion in technical knowledge over the last 50 years then the educational formation of engineers would far exceed the standard four or five years that is the norm. This means that an approach, other than a direct one, has to be adopted by engineers if a practical way of dealing with knowledge is to be realized within the practice of engineering. That in turns means choices have to be made constrained by limited resources an intrinsically engineering activity - concerning what might be termed the epistemological problem in engineering.

Regarding engineers 'operating at the interface between science and society' this is now of growing importance when one considers problems of supplying clean water or the linked challenge associated with climate change and the generation of energy to meet the demands of an ever expanding population. Whilst the knowledge associated with these complex societal issues is very different in nature to purely technical issues it is not of less importance. Further the responsibility, and that is what it is, to be able to enter into meaningful dialogue with society on technological change is not just a communications challenge but is itself an epistemological challenge bearing in mind the likely knowledge mismatch between the participants in any discussion. Providing society with an inadequate explanation of what is involved in technological change or indulging in an exercise of 'dumbing down' can only result ultimately in a loss of trust: and trust once lost is hard to re-gain. Hence there is a clear responsibility on engineers to meaningfully and accurately account for their understanding of the underlying knowledge and its related consequences involved in whatever technological-based discussion is taking place with and within society.

Formal engineering education has gone through a number of evolutions by which a craft based approach was in turn replaced by an empirical practice-based one, leading on first to the engineering science model and then followed by a systems oriented one. Further, as engineering split into a multiple of sub-disciplines from the initial mechanical, civil and electrical ones, to the wide range now in evidence across the world, each new area by choice or necessity adopted the style of education that seemed best to suit its needs. And all this is reflected in the range of approaches taken to the 'epistemological problem' - there being more relevant knowledge than can be absorbed. (See for example Bucciarelli, Coyle, McGrath 2009, p. 105)

In a paper presented at the Royal Academy of Engineering Antonio Dias de Figueirdo proposed a decomposition of the epistemology of engineering into four categories as follows: Engineering as Basic Science; Engineering as Social and Business Activity; Engineering as Design; and Engineering as Doing. With respect to the Basic Science the key features being its application to engineering, rigour, logistics, analysis, research and discovery. For Social and Business Activity the author identifies as key aspects socio-economic realities, social complexity, social and economic value, and satisfaction for end-users. As regards Engineering as Design 
the features noted include systems thinking, context, integrated representation, compromise, alternatives, incomplete knowledge, and non-scientific modes of thinking. Finally Engineering as Doing which concerns essentially the art of getting things done, overcoming barriers, the need for flexibility and adaptation. Without doubt this all points to the need to consider a complex concoction of knowledge elements with little in the way of a priori guidance as to how the bits fit together into a model. Custom and practice however has allowed some models to evolve and even if no claim can be made as to any deep philosophical justification at least experience has shown what is practicable from the perspective of educating engineers (de Figueiredo 2008).

Some other aspects of knowledge need to recognized if proper use, as would be the intention in engineering, of the application of specific bodies of knowledge. First, the range and extent of the applicability of such knowledge. Second, the provenance of the knowledge. This is especially the case concerning the widespread use of the web (Fox and Huang 2003). Third, how the knowledge is coded or represented, stored, transmitted, maintained and updated. This last feature is relevant to knowledge that encapsulates design methods, for example, where experience of its use inevitably leads to an updating of knowledge. Lastly, and not unique to engineering, there is the matter of secrecy or privacy where knowledge is withheld from a general audience either for commercial or strategic purposes and which at the very least raise ethical issues.

This chapter presents the knowledge relevant to engineering in the form of a three-layer model. The bottom or foundational layer represents fundamental knowledge, both rational and empirical, and which is commonly encountered through senior second-level and undergraduate years. The middle layer, building on the foundational layer represents the knowledge associated with the learning outcomes that students are expected master in their primary engineering degree program (i.e., domain knowledge). The final and top layer represents knowledge related to the competences that a practicing engineer should have achieved in order to be eligible to become the holder of the title Chartered Engineer or Professional Engineer. It should be said here that the proposed 3-layer model is representative of the epistemological basis found generally in English-speaking countries (e.g., United Kingdom, Ireland, Canada, United States). In many other countries this system of becoming a chartered or professional engineer does not exist. In these countries the formal training of engineers generally ends with the completion of a second cycle engineering degree at Master's level. Figure 1 shows these layers as a pyramid of engineering knowledge.

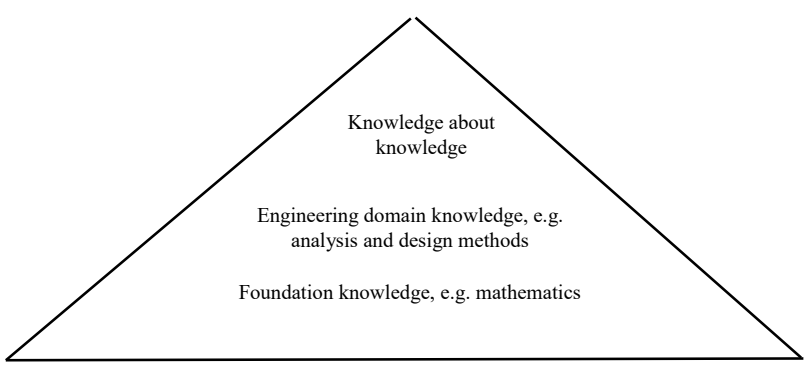

Figure 1. Pyramid of Engineering Knowledge 


\title{
Foundation Layer
}

Most educational models that reflect the various branches of knowledge found in engineering include the following subjects:

\author{
Mathematics \\ Science \\ Computer Science \\ Arts \& Craft Practice

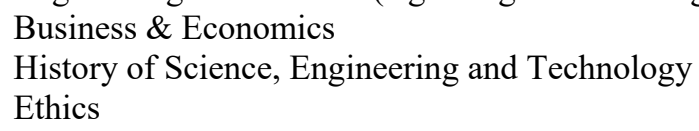

As the opening remarks to this chapter imply, the list could easily be expanded, for example to include languages, communications (in the sense of written and oral interactions) and critical thinking, to name just three topics. Depending on how one views engineering, the selection of subjects together with their associated knowledge base will vary. So in one sense there is not a unique epistemological foundational basis for engineering unlike, say, mathematics. But it would be wrong to say there are numerous and widely diverse bases: rather a more 'correct' model is one of a fuzzy superset. Equally well a mélange might be considered an appropriate description.

We will return later to the mélange and examine how the design of an engineering curriculum is approached but first a few thoughts on the subjects listed above. First, the model is not simple because of multiple dependencies and linkages. For example to understand some parts of physics requires specific elements of mathematics. For example, vector calculus is necessary to understand the meaning of Maxwell's equations in an electrical engineering program. Likewise, elements of a business course will rely on an understanding and use of statistical analysis. Ethics taught to engineers without context would be sterile but fortunately relevant cases abound in the history of science, engineering and technology. Given the relentless pressure to cram more subjects into already crowded curricula, advantage is often taken of this interconnectivity. Thus some subjects can be taught as embedded topics within another subject.

The demands made on the use of mathematics as an analysis tool vary from engineering domain to domain; whilst the modern undergraduate mathematics syllabus generally is not that different to that of say 40 years ago. However the methods and modes of instruction have changed. In terms of foundation knowledge, one of the biggest changes in engineering curricula that has occurred is the inclusion of additional science subjects. From its earliest development, engineering education has generally based its foundational knowledge on the physical sciences of physics and chemistry, together with mathematics. With the rapid development of engineering 
disciplines such as biomedical engineering, the inclusion of life sciences in the curriculum is compelling.

Computer science was first routinely introduced into engineering programs about 40 years ago as an analysis tool. Today, application software is an indispensible tool in engineering analysis, design and graphical representation. One of the challenges for educators is that over-reliance on software without a proper understanding of the underlying processes can lead to undesirable or unexpected outcomes. Generally the approach adopted is that the engineering student should in principle be able to carry out a design without using a software package. This is perhaps akin to the merits of a pilot being able to manually fly an airliner as well as being confident that the autopilot can perform what is required in both routine and exceptional circumstances. However, computer systems and applications continue to become increasingly sophisticated, presenting continued challenges to curriculum designers. In such circumstances where lies the epistemological basis of engineering?

Mathias Heymann has written about the competing claims of 'art' and science, mainly in a German context, describing as a pendulum movement how in turn one and then the other contributed to engineering design methodology in the period 1850 to 2000 . In some quarters as an engineering science approach was developed there was a tendency to downplay the role of arts and craft practice (Heymann 2009). Apprenticeships which were once a strong feature in engineering education in the UK served many purposes but certainly the mentoring role by which new recruits served with a 'master' to acquire craft skills was of great importance.

Michael Polanyi introduced into philosophy the term tacit knowledge and this concept applies to how some elements that are not explicit are an essential part of the engineering and engineering craft milieu (Polanyi 1958). Engineering "knowhow' is not confined to such tacit knowledge. For example, across many engineering disciplines much of the relevant working knowledge is codified (hence explicit) in one form or another often with customized software support. This enables both efficiency and the maintenance of minimum standards.

Economics and business are important not only for the sake of understanding how business and commerce work on a national and global scale but also because engineers are likely to move into senior management positions at a later stage in their careers. Younger engineers are also attracted into finance where the coupling of mathematics with a judgment of what makes sense (allegedly a characteristic of engineers) is a prized asset.

Ethics is given a high relevance amongst undergraduate engineering programmes not only by virtue of accreditation criteria but also with those regulating for practicing Professional Engineers or Chartered Engineers and who are members of professional bodies or institutions with Codes of Ethics.

Finally, history of science, engineering and technology is important, first because it helps undergraduate engineers formulate an identity. Because so much of engineering is hidden from view the understanding of what it means to be an engineer does not come easily to prospective or junior undergraduate engineers. The situation is very different in medicine for example where from an early age either through direct personal experience of healthcare systems or exposure to media (TV and film) dealing with how doctors and nurses work, children and then teenagers have a firm concept of what it means to be a doctor or nurse. That is not to say that medical student's identity is fully formed but it is well in advance of the situation amongst first year engineers. 
The above overview is not sufficient however to describe engineering and its overall knowledge base but it does articulate the elements of the foundations. Put another way it is as if an orchestral piece of music work was defined by limiting discussion to the characteristics of the various instruments deployed. To an audience the music played depends on the selection of instruments used and the skill of the players, but above that there is the nature and quality of the music being played. The composer set out with an objective in mind and the degree to which that objective is judged to have been met is of course always an open question. Engineering has similar features in that the engineer's 'composition' might or might not be valued by society acting as an 'audience'.

The next section looks at the role of the material in the foundation layer in contributing to a set of learning outcomes which in turn have an associated engineering knowledge identity.

The Middle Layer of Model: Knowledge Associated with Engineering Program Learning Outcomes

A multi-nation European initiative resulted in the establishment of the European Network for Accreditation of Engineering Education which authorizes accreditation and quality assurance agencies to award the EUR-ACE® label to accredited engineering degree programs. In addition to reviewing both the quality of the teaching facilities and the lecturing staff, importance is put on whether the program enables students to achieve a set of outcomes (ENAEE). The six Program Outcomes are:

- Knowledge and Understanding;

- Engineering Analysis;

- Engineering Design;

- Investigations;

- Engineering Practice;

- Transferable Skills.

Currently Europe classifies programs as First Cycle, normally of three years duration, and Second Cycle normally together with the First Cycle of five years duration. The First Cycle is in essence a Bachelor program and the Second Cycle a Masters Program. In some cases the Master component is a two-year 'add-on' to the Bachelor program, and in other cases the Master is an $a b$ initio five-year program. ENAEE specifies a range of competences under each of the six learning outcomes as follows:

Knowledge and Understanding:

First Cycle graduates should have:

- knowledge and understanding of the scientific and mathematical principles underlying their branch of engineering;

- a systematic understanding of the key aspects and concepts of their branch of engineering;

- coherent knowledge of their branch of engineering including some at the forefront of the branch; 
- awareness of the wider multidisciplinary context of engineering.

Second Cycle graduates should have:

- an in-depth knowledge and understanding of the principles of their branch of engineering;

- a critical awareness of the forefront of their branch.

\section{Engineering Analysis:}

First Cycle graduates should have:

- the ability to apply their knowledge and understanding to identify, formulate and solve engineering problems using established methods;

- the ability to apply their knowledge and understanding to analyse engineering products, processes and methods;

- the ability to select and apply relevant analytic and modelling methods.

Second Cycle graduates should have:

- the ability to solve problems that are unfamiliar, incompletely defined, and have competing specifications;

- the ability to formulate and solve problems in new and emerging areas of their specialisation;

- the ability to use their knowledge and understanding to conceptualise engineering models, systems and processes;

- the ability to apply innovative methods in problem solving.

Engineering Design:

First Cycle graduates should have:

- the ability to apply their knowledge and understanding to develop and realise designs to meet defined and specified requirements;

- an understanding of design methodologies, and an ability to use them.

Second Cycle graduates should have:

- an ability to use their knowledge and understanding to design solutions to unfamiliar problems, possibly involving other disciplines;

- an ability to use creativity to develop new and original ideas and methods;

- an ability to use their engineering judgement to work with complexity, technical uncertainty and incomplete information.

Investigations:

First Cycle graduates should have:

- the ability to conduct searches of literature, and to use data bases and other sources of information;

- the ability to design and conduct appropriate experiments, interpret the data and draw conclusions;

- workshop and laboratory skills.

Second Cycle graduates should have:

- the ability to identify, locate and obtain required data;

- the ability to design and conduct analytic, modelling and experimental investigations; 
- the ability to critically evaluate data and draw conclusions;

- the ability to investigate the application of new and emerging technologies in their branch of engineering.

\section{Engineering Practice:}

First Cycle graduates should have:

- the ability to select and use appropriate equipment, tools and methods;

- the ability to combine theory and practice to solve engineering problems;

- an understanding of applicable techniques and methods, and of their limitations;

- an awareness of the non-technical implications of engineering practice.

Second Cycle graduates should have:

- the ability to integrate knowledge from different branches, and handle complexity;

- a comprehensive understanding of applicable techniques and methods, and of their limitations;

- a knowledge of the non-technical implications of engineering practice.

\section{Transferable Skills:}

First Cycle graduates should be able to:

- function effectively as an individual and as a member of a team;

- use diverse methods to communicate effectively with the engineering community and with society at large;

- demonstrate awareness of the health, safety and legal issues and responsibilities of engineering practice, the impact of engineering solutions in a societal and environmental context, and commit to professional ethics, responsibilities and norms of engineering practice;

- demonstrate an awareness of project management and business practices, such as risk and change management, and understand their limitations;

- recognise the need for, and have the ability to engage in independent, lifelong learning.

Second Cycle graduates should be able to:

- fulfil all the Transferable Skill requirements of a First Cycle graduate at the more demanding level of Second Cycle;

- function effectively as leader of a team that may be composed of different disciplines and levels;

- work and communicate effectively in national and international contexts.

Though the language used in setting out the learning outcomes is in the form of expressing an ability it is clear that behind each proficiency there is a knowledge that is to be applied. In some learning outcomes the knowledge is obvious but in others it is implicit. The first Learning Outcome (Knowledge and Understanding) has a straightforward link to the foundational layer through 'scientific and mathematical principles', but the added knowledge required for a 'systematic understanding ...' is not so straightforward. Nor is it a simple matter to articulate exactly what this added 
knowledge consists of, even though its application might be perfectly clear. Nevertheless there is a specific form of knowledge required if a systemic understanding of an engineering task is to be carried out properly. With the second Learning Outcome (Engineering Analysis) there is another type of knowledge required in the 'understanding to conceptualise engineering models, systems and processes'. In the third Learning Outcome (Engineering Design) a different knowledge base is necessitated for 'an understanding of design methodologies'. To know the merits of potential design methodologies and then be sufficiently knowledgeable to choose the 'right' one is a valued knowledge based skill. (In passing it is noted that some authors make a distinction between knowledge and wisdom where the latter concerns the ability that comes with experience to wisely navigate through sets of knowledge.) The set of six learning outcomes have precursor knowledge starting points. And it should be clear that such knowledge is very different in character to the knowledge in the foundational layer. In this way the nature of engineering emerges but that is not the end of the matter.

The next section describes the third layer 'Competences', which, building on the knowledge of the two lower layers and added to relevant work experience, leads to the state of knowledge that an engineer must reach to be considered a Chartered Engineer or Professional Engineer. UK, Ireland and Australia amongst others use the term Chartered Engineer (CEng), whilst Canada and the United States amongst others use the term Professional Engineer (PE).

\section{The Top Layer of the Model: Knowledge Associated with the Competences Re- quired of Chartered or Professional Engineers}

To set a context, professional bodies such as Engineers Ireland, consider that the formation of an engineer consists of two parts. The first part refers to the educational formation usually culminating in an accredited Bachelor or Master degree. To aid the mobility of engineers worldwide and ensure transparency of engineering qualifications, many countries have signed agreements or accords by which accredited degrees are mutually recognised. The Washington Accord is an international agreement entered into by Engineers Ireland with other professional bodies in the UK, USA, Canada, Australia, New Zealand, Hong Kong-China, South Africa, Japan, Korea, Singapore, Malaysia and Taiwan. Through this Accord, the signatories accept each other's accreditation decisions thereby enabling mutual recognition of each signatory's engineering degree programs. The second part refers to post degree experience gained in relevant engineering work situations. The total period of formation is a minimum of eight years. The following is the definition of a professional engineer recognised by the Council of Engineers Ireland for the title Chartered Engineer and is the definition adopted in 1960 by the Conference of Engineering Societies of Western Europe and the United States of America (UESEC): 


\begin{abstract}
progress in his/her branch of engineering science by consulting newly published works on a worldwide basis, assimilating such information and applying it independently. $\mathrm{He} / \mathrm{she}$ is thus placed in a position to make contributions to the development of engineering science or its applications. His/her education and training will have been such that he/she will have acquired a broad and general appreciation of the engineering sciences as well as thorough insight into the special features of his/her own branch. In due time he/she will be able to give authoritative technical advice and to assume responsibility for the direction of important tasks in his/her branch.
\end{abstract}

To become a Chartered Engineer, in most if not all relevant jurisdictions, an applicant submits a mandatory report which, if accepted, is followed up by an interview conducted by a panel of trained interviewers. The key areas explored are the five competences that the applicant must demonstrate they have attained.

- Competence 1: Use a combination of general and specialist engineering knowledge and understanding to optimise the application of existing and emerging technology.

- Competence 2: Apply appropriate theoretical and practical methods to the analysis and solution of engineering problems.

- Competence 3: Provide technical, commercial and managerial leadership.

- Competence 4: Use effective communication and interpersonal skills.

- Competence 5: Make a personal commitment to abide by the appropriate code of professional conduct, recognising obligations to society, the profession and the environment.

In Competence 1 it would be expected that a Chartered Engineer 'deepens their knowledge base systematically through research and experimentation', and 'extends knowledge of related disciplines or fields and fosters co-operation across discipline boundaries to identify future potential opportunities'. For Competence 2, Chartered Engineers should have the capacity to 'exercise original thought in synthesising satisfactory outcomes to engineering challenges'. Within Competence 5, Chartered Engineers are expected to 'give evidence, express opinions or make statements in an objective and truthful manner and on the basis of adequate knowledge'. This last requirement is a powerful one that should apply to all professionals as it demands that the individual operates within a knowledge space which they have the responsibility of judging to be adequate. In other words, this is an injunction not to operate outside one's competence (or knowledge boundary). As an aside there are those in both Science and Engineering who have proposed a Hippocratic Oath adapted to their respective professions, see for example William Grimson \& Mike Murphy (Grimson and Murphy 2013). Whilst few professional bodies have adopted such an oath it at least makes sense to discuss the underlying issues with students in their undergraduate classes and for codes of ethics to reflect the intentions involved.

At this stage a general picture should have emerged as to the epistemological web inhabited by engineers. But it is still very complex and difficult if not impossible for any one individual to master. This is why pragmatic approaches abound in engineering. One such approach is based on the use of heuristics and an example is presented later. But by far the most important approach encountered in engineering to control what otherwise would be an impossible situation - building from basics through to producing an optimum solution for any particular challenge - is the use of standardised (well-tested and widely adopted) methods. Another aspect of engi- 
neering is the positive role failure plays in developing new knowledge and refining methods. The next section discusses heuristics, standardised methods, and the role of failure.

\section{Dealing with Complexity}

\section{Heuristics}

Strategies that reflect constraints with respect to the acquisition of relevant knowledge to solving a particular problem include approaches that intentionally seek to obtain a solution through processes that are not in fact guaranteed to be valid. The use of a rule-of-thumb falls into this category. This might seem strange and antiscientific but engineering puts more store on getting a result than proceeding elegantly without result. It is not that elegance is discounted, but more a reflection that elegance is not always possible. Billy Koen has written extensively about heuristics which he describes in essence as doing the best in an inadequately understood situation within available resources (Koen ). In fact Koen makes the claim that all engineering is heuristic. There is some truth to this claim but it should not be taken literally. Many engineering challenges can be addressed without recourse to heuristics, but they do have a place especially when applied intelligently. For a general introduction, not specific to engineering, the reader should consult Michalewicz Zbigniew, David Fogel's book 'How to Solve it: Modern Heuristics'.

To illustrate the heuristic approach with a simple example and also to flavor why it is an attractive option when intelligently applied, consider the following problem. A very long ladder network consists of 1-ohm resistors as shown in Figure 2. The problem is to determine the input resistance at terminals $\mathrm{TT}^{\prime}$. One line of attack is to truncate the network at $\mathrm{AA}^{\prime}$ and calculate the input resistance when (a) a shortcircuit is created at $\mathrm{AA}^{\prime}$ and (b) when an open circuit is allowed at $\mathrm{AA}^{\prime}$.

All components are resistors with $R=1 \Omega$

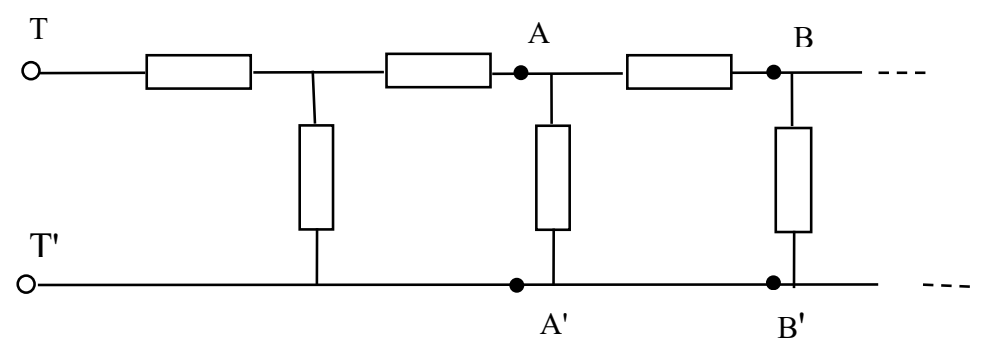

Figure 2. Long resistor ladder network with equal components

Using the simple electricity laws of calculating the resistance of resistors in series and parallel quickly leads to the results:

$$
\mathrm{R}_{\text {in }}\left(\text { open-circuit) }=2 \Omega \text { and } \mathrm{R}_{\text {in }}(\text { short-circuit })=1.5 \Omega\right.
$$


Logically, the input resistance of the full ladder network must lie between these two values. An improved bracketing could be obtained by truncating the network at BB' in which case the results are as follows:

$$
\mathrm{R}_{\mathrm{in}}(\text { open-circuit })=1.666 \Omega \text { and } \mathrm{R}_{\mathrm{in}}(\text { short-circuit })=1.6 \Omega
$$

The heuristic 'solution' is then found from the upper and lower bounds by taking the geometric mean of these two values yielding 1.633. Two points can be made. First, adopting a truncation strategy allowed both the upper and lower bounds to be calculated with zero error. Second, no justification can be given for how the final result is obtained and the alternative of using an arithmetic mean would have been equally justified. However the solution obtained cannot be too far from the true value due to the approach used in the bracketing between the upper and lower bounds. As it transpires the true result is $1.618 \Omega$ which can be found in a number of different ways. But that is not the point of the example; rather an intelligent approach using easily available knowledge facilitated a sensible application of heuristics. Whether the bracketed solution is usable of course depends on the context in which the original problem arose.

\section{Role of Failure in Engineering}

Engineering is largely evolutionary wherein progress is incremental based on a selection process (see Grimson and Murphy 2009). The selection process is not just concerned with what is 'good', the 'bad' is equally important. In the extreme case the 'bad' can represent a total failure of a system or some vital component of that system. Henry Petroski has written much about failure in engineering and whilst failure is never intentional it is to some extent inevitable, but any failure comes with the benefit that post-failure analysis can result in new knowledge or at least information $^{1}$ that can reduce future accidents (Petroski 1985). Unfortunately failure can be caused by poor management decision-making (see for example the Challenger Shuttle disaster) and negligence (Kansas City Hyatt Regency Hotel walkway collapse). But it is failure when neither poor management nor negligence is involved that generates the most useful technical insight leading to new engineering knowledge. One example is the well documented collapse of the Tacoma Narrows Bridge. What transpired in investigating this failure was that wind-induced instability (aeroelastic flutter) caused the bridge to collapse. The mode of failure was a new one and forced bridge designers armed with this new knowledge to take into account aeroelastic flutter.

Failure does not have to occur in live situations to generate new knowledge. In fact most failures occur under laboratory or testing conditions. The use of windtunnels and hydro-models for example are engineering substitutes for almost intractable mathematical calculations. And today the use of computers in modelling in almost all branches of engineering is so advanced that some educationalists are being forced to re-think how design is taught. Another challenge arises when engineering simply becomes an academic pursuit divorced from engineering practice with its rich experience of failure. Steen Christensen and Byron Newberry in reviewing academic drift in engineering note that 'the process whereby knowledge derived from 
practical engineering work experience and intended to be useful for industrial practice gradually loses its close ties to practice (Christensen and Newberry 2014). Instead engineering knowledge becomes increasingly theoretical and oriented toward engineering disciplines, including mathematics and natural science'. The danger here is analogous to a medical doctor losing sight of his/her patient!

\section{The Role of Standardized Methods}

There are multiple reasons for the use of standardized methods. Accumulated knowledge is encapsulated in such methods in the sense that they become evidencebased. Another reason is that safety concerns are addressed by restricting options that might with experience prove to be poor. The early history of ASME, founded in 1880, was inextricably linked with the problems of boilers exploding. The ASME website (see www.asme.org/engineering-topics/articles/boilers/the-history-of-asmesboiler-and-pressure) provides the background:

The ASME Boiler and Pressure Vessel Code (B\&PVC) was conceived in 1911 out of a need to protect the safety of the public. This need became apparent shortly after the conception of the steam engine in the late 18th century. In the 19th century there were literally thousands of boiler explosions in the United States and Europe, some of which resulted in many deaths. The consequences of these failures were locally focused and, other than one or two, received minimal national or international attention. Undoubtedly, one of the most important failures that proved the need for Boiler Laws was the boiler explosion that occurred at the Grover Shoe Factory in Brockton, Massachusetts on March 10, 1905. That incident resulted in 58 deaths and 117 injuries and completely levelled the factory. This catastrophe brought attention to the need to protect the public against such accidents with pressure-retaining equipment.

The outcome was the development of a code resulting in the publishing in 1915 of The Boiler and Pressure Vessel Code. This code set standards covering the rules for fabricating a component, materials that are to be used, welding, testing, and rules that permit the use of materials and alternative methods of construction. The work in devising this code must have involved many experts but the value to other engineers and society more than repaid the initial effort required. The central point is that knowledge became encoded in a particular and useful manner and then made available to others. This encoding might be thought of as creating second-order knowledge or knowledge about knowledge.

There are countless examples in engineering where knowledge is encapsulated in the form of codes, standards, guidelines, methods etc. and they all serve the purpose of engineering work proceeding in an efficient, effective, safe, and organised manner. Further, they serve the engineering community by providing a 'language' and a process by which enhancements can be made. Innovation it is claimed can be stifled by too rigorous an adherence to codes or standards. But in the longer term successful innovations yield their own standards, the internet for example. Finally, codes, standards, and approved methods allow engineers to proceed without having to revert to first principles every time a new task commences. Nor do engineers need to spend time and effort solving problems already solved many times over. Instead engineers are more readily freed to build on the work of previous generations.

\section{Relevant importance of various skills and knowledge}


It is one thing to identify what skills and knowledge need to be developed within an engineering program it is another matter entirely to assign corresponding weight in the design of a curriculum. In a report by the Center for the Advancement of Engineering Education data is presented indicating the importance of skills and knowledge in rank order as perceived by senior engineering students (Atman et al 2010). In descending order the relative importance is ranked as follows: Problem solving (73\%); Communication; Teamwork (61\%); Engineering analysis; Ethics (40\%); Design; Creativity; Life-long learning; Math (19\%); Data analysis; Engineering tools; Leadership; Business knowledge; Science (13\%); Management skills; Professionalism (11\%); Conducting experiments; Global context; Societal context; Contemporary issues. Whether this ranking reflects what students have been offered or what they would like to have been offered is open to question. But the list and ranking is a good description of the challenges in designing a fit for purpose curriculum.

Design as a general engineering activity is one of the hardest to characterize. And the necessary knowledge underpinnings include much of what has been stated already (Science, Math, Analysis etc). But there is much more to design. Another dimension is outlined in the above report, namely the most important Design Activities. These range from Understanding the problem (most important) to Identifying constraints, Testing, Modeling, Prototyping, Iterating to Abstracting (least important). The point that is emphasized here is that each activity must be supported by some form of knowledge if the engineer is to know how to proceed in a sensible manner rather than simply by trial and error. It follows that this spectrum of activities must be taken account of in the formation of an engineer (undergraduate, postgraduate and professional undertakings)

\section{Conclusion}

At first glance epistemology is the most easily understood of the five classical branches of philosophy (epistemology, metaphysics, logic, aesthetics and ethics). We are told that we live in a modern world that is knowledge driven and undoubtedly our ready access to knowledge is well supported through the use of information technology. We, it would seem, use, create and modify, store and transmit knowledge on a routine basis in our everyday lives, and so assume an easy familiarity with it. But you don't need to be a philosopher to realize that epistemology is in fact a most difficult and complex thing. From a very practicable perspective the issues surrounding determining provenance, the ability to authenticate, and understanding the limitations of knowledge, all have particular significance for engineering. With the possible exception of mathematics which since it is strictly rational can be excluded, all branches of knowledge on which engineering is based is to a greater or lesser extent a structure built on shifting sands. This is not to say engineering is useless or in some way defective. Rather it points to the need to constantly update its knowledge base knowing that circumstances change and as a consequence fresh evidence surfaces.

According to James Boswell, Samuel Johnson held that there are two kinds of knowledge, the first being that which we know ourselves, the second being knowing where to find what we wish to know. An engineer might well add a third kind, namely knowing when or why to search for new knowledge or update existing 
knowledge. It is not too surprising then that David Goldberg in a talk given at the Royal Academy of Engineering in London stated that engineering is epistemologically weak (see http://www.slideshare.net/deg511/engineering-in-context-theprofessional-and-institutional-setting Slide 37). In the first place engineering is a net borrower (particularly mathematics and the sciences), and in the second place engineering knowledge is subject to gradual and occasionally abrupt change. One can accept therefore the 'weakness' assertion but this is not necessarily a negative attribute. At its simplest the demands made of engineering to solve problems, address challenges, and to create that which never previously existed means that the 'strength' of engineering epistemology is not of great importance. Instead the usability of the knowledge is the critical factor. Even a certain lack of consistency in the knowledge used can be tolerated in engineering provided the impact of such inconsistency is known and allowed for in the course of undertaking the work involved. This is analogous to the heuristic method discussed previously in this chapter where there is a need to do the best one can, in conditions that are not ideal.

Another issue centers on the definition of knowledge. The classical definition, going back to Plato, is that knowledge is 'justified true belief'. In an engineering context 'justified' is generally not a black or white attribute, in practice there would be degrees of justification depending on the context. This conditionality of engineering knowledge requires judgment to be exercised by engineers, a skill that comes with experience. It is tempting to refer to such judgment as being the application of wisdom; wisdom being the good or best use of available knowledge, and one could say it is a form of knowledge about knowledge.

Engineering relies on and is supported by the rational knowledge that is science and the empirical knowledge that is the sciences. As explained earlier there are other foundational areas too. The middle layer represents the core of what some would say is 'engineering' where the knowledge of how to carry out a wide range of activities is contained. The ability to determine requirements, analyze, design, test, evaluate, review - all these are required of an engineer in whatever sub-discipline of engineering they operate. The top layer of knowledge characterizes the deep understanding of the underlying layers by which engineering work can be carried out using appropriate methods and when necessary devising new approaches. The epistemological basis of engineering poses descriptive difficulties but there is an underlying structure that is both robust and resilient, largely determined by educationalists and practitioners who have built on a wealth of experience. New knowledge is created and old knowledge modified or discarded but the structure in which it fits remains constant. It is this structure that allows engineering to proceed without being submerged in sea of knowledge.

\section{References}

Atman, C; Sheppard , S; Turns, J; Adams, R; Fleming L; Stevens, R; Streveler, R; Smith, K; Miller, R; Leifer, J; Yasuhara, K; Lund, D. Enabling Engineering Student Success - the Final Report for the Centre for the Advancement of Engineering Education. Morgan\& Claypool Publishers, 2010.

Boswell, James (1791). The Life of Samuel Johnson. Available at: http://www.gutenberg.org/ebooks/ 1564.

Bucciarelli, Louis; Coyle, Eugene, and McGrath, Denis (2009). Engineering Education in the US and the EU. In: Christensen, Steen Hyldgaard; Delahousse, Bernard, and Meganck, Martin (eds.). Engineering in Context. Academica, Aarhus, Chapter 5.

Christensen, Steen Hyldgaard, and Newberry, Byron (2014). The Role of Research in Academic Drift Processes in European and American Professional Engineering Education outside the University Sec- 
tor. In: Christensen, Steen Hyldgaard; Didier, Christelle; Jamison, Andrew; Meganck, Martin; Mitcham, Carl, and Newberry, Byron (eds.). International Perspectives on Engineering Education. Springer, Chapter 2.

De Figueiredo, Antonio Dias. Toward an Epistemology of Engineering. Workshop on Philosophy \& Engineering. Royal Academy of Engineering, London 2008. http://www.slideshare.net/adfigueiredo/toward-an-epistemology-of-engineering-presentation.

Engineers Ireland (2012). Chartered Engineer. Regulations for the Title of Chartered Engineer. Available at: $\quad$ www.engineersireland.ie/EngineersIreland/media/SiteMedia/membership/professional-titles/ Chartered-Engineer-Regulations-2012.pdf. 22 - 27 (accessed 29 August 2013).

European Network for Accreditation of Engineering Education (ENAEE). The EUR-ACE System. Available at:http://www.enaee.eu/eur-ace-system (accessed 29 August 2013).

Fox, M; Huang, J. Knowledge Provenance: An Approach to Modelling and Maintaining the Evolution and Validity of Knowledge. EIL Technical Report. University of Toronto 2003.

Grimson, William, and Murphy, Mike (2009). An Evolutionary Perspective on Engineering Design. $n$ : Christensen, Steen Hyldgaard; Delahousse, Bernard, and Meganck, Martin (eds.). Engineering in Context. Academica, Aarhus, Chapter 13.

Grimson, William, and Murphy, Mike. A Hippocratic Oath for Engineers. In: Michelfelder, Diane; McCarthy, Natasha, and Goldberg, David (eds.). Chapter 15. Philosophy and Engineering: Reflections on Practice, Principles, and Process. Springer, Dordrecht, 2013.

Heymann, Matthias (2009). "Art” or Science? Competing Claims in the History of Engineering Design. In: Christensen, Steen Hyldgaard; Delahousse, Bernard, and Meganck, Martin (eds.). Engineering in Context. Academica, Aarhus, Chapter 11.

Koen, Billy (2003). The Engineering Method and the Heuristic: A Personal History. Oxford University Press.

Petroski, Henry (1985). To Engineer is Human: the Role of Failure in Successful Design. St. Martin's Press.

Polanyi, Michael (1958). Personal Knowledge: Towards a Post-Critical Philosophy. University of Chicago Press.

Zbigniew, Michalewicz, and Fogel, David B. (2004). How to Solve it: Modern Heuristics (2 ${ }^{\text {nd }}$ ed.). Springer Verlag. 